\title{
SURGICAL MYOCARDIAL REVASCULARIZATION OF PATIENTS WITH ISCHEMIC CARDIOMYOPATHY AND SEVERE LEFT VENTRICULAR DISFUNCTION
}

\author{
André L. Hovnanian, ${ }^{\mathrm{I}}$ Alexandre de Matos Soeiro, ${ }^{\mathrm{I}}$ Carlos Vicente Serrano Jr, \\ Sérgio Almeida de Oliveira, ${ }^{\text {II }}$ Fábio B. Jatene," Noedir A. G. Stolf,, José A. F. \\ Ramires $^{\text {III }}$
}

doi: 10.1590/S1807-59322010000100002

Hovnanian AL, Soeiro AM, Serrano Jr CV, de Oliveira SA, Jatene FB, Stolf NAG, Ramires JAF. Surgical myocardial
revascularization of patients with ischemic cardiomyopathy and severe left ventricular disfunction. Clinics. 2010;65(1):3-8.

OBJECTIVE: To determine long-term survival, identify preoperative factors predictive of a favorable outcome, and assess functional improvement after coronary artery bypass grafting in patients with advanced left ventricular dysfunction.

METHODS: Between 1995 and 2001, 244 patients who underwent coronary artery bypass grafting and had a preoperative left ventricular ejection fraction less than or equal to $35 \%$ were included. left ventricular ejection fraction was determined by uniplanar or biplanar ventriculography during left heart catheterization. Indication for surgery was predominance of tissue viability. Functional improvement was evaluated through echocardiography and gated scintigraphy at exercise/ rest. Survival was determined by Kaplan-Meier analysis.

RESULTS: Mean left ventricular ejection fraction was $29 \pm 4 \%$ (ranged from $9 \%$ to $35 \%$ ). An average of 3.01 coronary bypass grafts per patient were performed. In-hospital mortality was $3.7 \%$ ( 9 patients). The 4-year survival rate was $89.7 \%$. Multivariate correlates of favorable short- and long-term outcome were preoperative New York Heart Association Funcional classification for congestive heart failure class I/II, lower PAsP, higher left ventricular ejection fraction and gated left ventricular ejection fraction Ex/Rest ratio $>5 \%$. Left ventricular ejection fraction rise from $32 \pm 5 \%$ to $39 \pm 5 \%, p<0.001$. Gated left ventricular ejection fraction at exercise/ rest increased markedly after surgery: from $27 \pm 8 \% / 23 \pm 7 \%$ to $37 \pm 5 \% / 31 \pm 6 \%, p<0.001$.

CONCLUSIONS: In selected patients with severe ischemic left ventricular dysfunction and predominance of tissue viability, coronary artery bypass grafting may be capable of implement preoperative clinical/ functional parameters in predicting outcome as left ventricular ejection fraction and gated left ventricular ejection fraction at exercise/ rest.

KEYWORDS: Coronary artery bypass grafting surgery. Left ventricular dysfunction. Myocardial revascularization. Functional improvement. Preoperative predictive factors.

\footnotetext{
I Unidade Clínica de Coronariopatia Aguda, Instituto do Coração (InCor), Hospital das Clínicas da Faculdade de Medicina da Universidade de São Paulo - São Paulo/SP, Brazil.

II Departamento de Cirurgia, Instituto do Coração, Hospital das Clínicas da Faculdade de Medicina da Universidade de São Paulo - São Paulo/SP, Brazil. III Divisão de Cardiologia Clínica, Instituto do Coração, Hospital das Clínicas da Faculdade de Medicina da Universidade de São Paulo, São Paulo/ SP,Brazil.

Email: ahovnanian@uol.com.br

Tel.: 55113066.7427

Received for publication on July 21, 2009

Accepted for publication on September 09, 2009
}

\section{INTRODUCTION}

Coronary artery bypass grafting $(\mathrm{CABG})$ has achieved a well-established role on the management of patients with coronary artery disease (CAD) and left ventricular disfunction, providing long-term benefits superior to medical therapy ${ }^{1-5}$ However, when considering patients with severe left ventricular dysfunction (left ventricular ejection fraction $[\mathrm{LVEF}]<30 \%$ ), such a success was obtained 
very gradually. Provided by the advances on preoperative care stabilization, such as by the prophylactic use of intraaortic balloon pump (IABP) ${ }^{6-8}$ on surgical technique by means of new cardioplegic solutions and shorter cross clamp and cardiopulmonary bypass times, associated with the improvement on intensive postoperative care, in-hospital mortality rates decreased about four times ${ }^{9-19}$ during the last two decades, which makes the procedure a very suitable implement for the management of these particular population. Nevertheless, a judicious evaluation of preoperative clinical and functional parameters should be undertaken when selecting patients for surgery, especially for those with extremely poor function.

The present retrospective study was performed to determine long-term survival, identify preoperative factors predictive of a favorable outcome, and assess functional improvement after CABG in patients with advanced left ventricular dysfunction.

\section{MATERIALS AND METHODS}

All patients who underwent CABG between 1998 and 2004, and who had a preoperative $\mathrm{LVEF} \leq 35 \%$ were included in this analysis. There were 153 male and 91 female patients. This study was approval by Ethics Committee. The LVEF was estimated by either uniplanar or biplanar ventriculography during left heart catheterization (table 1).

Data were recovered retrospect from medical records and congestive heart failure class were rated using classification of New York Heart Association.

Indication for surgery was based on predominance of tissue viability, defined as maintained Thallium-201 uptake in more than $50 \%$ of dyssynergic segments at rest.

All procedures were performed using cardiopulmonary bypass and hypothermia of $32^{\circ}$ Centigrade. Roller pump and membrane oxygenators were used in all of these procedures. Distal anastomoses were performed during cross clamp time and aortic anastomoses were carried out using tangential aortic clamping with empty fibrillating or beating heart. Total number of grafts was 736. Mean number of grafts per patient was 3.01 (77\% with internal thoracic artery) and $17 \%$ had concomitant mitral valve replacement or repair (table 2). Cold crystalloid cardioplegia (St. Thomas solution) insertion was antegrade and intermittent (into grafts being already constructed).

Patients performed bidimensional echocardiography and gated scintigraphy before surgery and at a median time of 12 months after that, in order to establish functional improvement.

\section{Statistical methods}

All data are presented as proportions or as mean \pm standard deviation. Comparisons of means as appropriate were determined by using paired t-tests. Difference of proportions was evaluated by using fisher exact test. Univariate analysis was employed to determine the association between concomitant variables and death. Multivariate analysis was performed by logistic regression analysis. Survival was determined by Kaplan-Meier analysis. Statistical significance was considered with $p<0.05$. All analysis were performed by SPSS 10.0 statistical software package.

\section{RESULTS}

The mean age of patients was $61 \pm 7$ years old. Risks for coronary artery disease are shown in table 1. Fifty-nine percent of patients had previous myocardial infarction. Prior revascularization and prior percutaneous transluminal coronary angioplasty were present in $24 \%$ and $49 \%$, respectively. Seventy-two percent of patients had angina at the time of operation. Class III or IV of New York Heart Association Funcional classification for congestive heart failure (NYHA FCCHF) was present in more than $41 \%$ of patients and $87 \%$ had multivessel disease. Mean LVEF was $29 \pm 4 \%$ (ranged from $9 \%$ to $35 \%$ ) and mean LVEDP was $32 \pm 7 \mathrm{mmHg}$ (ranged from 11 to $44 \mathrm{mmHg}$ ). Thirty-one patients (12.7\%) had LVEF < 15\%, 140 (57.4\%) between $16 \%$ and $25 \%$, and $73(29.9 \%$ ) between $26 \%$ and $35 \%$ (table 1). After four years of follow-up, we had $94 \%$ of patients included in study.

An average of 3.01 coronary bypass grafts per patient were performed ( $77 \%$ with internal thoracic artery) and $17 \%$ had concomitant mitral valve replacement or repair (table 2).

Mean cardiopulmonary bypass time was $65 \min$ (40-92), mean cross clamp time was $42 \min (20-51)$.

Morbidity according to preoperative LVEF are shown in table 3 .

In-hospital mortality was $3.7 \%$ (9 patients). Causes of death included hemorrhage (4 patients), infection (3 patients) and myocardial infarction ( 2 patients). The 4-year survival rate was $89.7 \%$. There were $16(6,5 \%)$ cases of stroke in post-operatory. In-hospital mortality was as high as $13 \%$ for patients with LVEF $<15 \%, 25 \%$ for PAsP $>70 \mathrm{mmHg}$, and $10 \%$ for CHF IV patients. Kaplan-Meier survival curves according to preoperative parameters are shown in figure 1 .

Multivariate analysis showed positive correlation between favorable short and long-term outcome and preoperative NYHA FCCHF class I/II $(p=0,0072)$, lower PAsP $(p<0,0001)$, higher LVEF $(p=0,0001)$, and gated LVEF Ex/Rest ratio $>5 \%(p<0,0001)$. At a median time of 12 months after surgery, 201 patients repeated bidimensional echocardiography and 173 patients performed radioisotopic evaluation of LVEF. LVEF rose from $32 \pm 5 \%$ to $39 \pm 5 \%$, 
Table 1 - Baseline characteristics

\begin{tabular}{|c|c|}
\hline & $\mathrm{n}=244$ \\
\hline Age, y & $61 \pm 7$ \\
\hline Male sex, $\%$ & $153(62.7)$ \\
\hline Female sex, $\%$ & $91(37.3)$ \\
\hline \multicolumn{2}{|l|}{ Medical history, $\%$} \\
\hline Hypertension & 75 (30.7) \\
\hline Hypercholesterolemia & $82(33.6)$ \\
\hline Diabetes mellitus & $41(16.8)$ \\
\hline Smoking & $93(38.1)$ \\
\hline Previous MI & $144(59.0)$ \\
\hline Months after MI & $5.3 \pm 1.6(2.5-49)$ \\
\hline \multicolumn{2}{|l|}{ Site of MI, \% } \\
\hline undefined or LBBB & $62(43)$ \\
\hline anterior & $56(38.9)$ \\
\hline inferior & $29(20.1)$ \\
\hline lateral & $7(4.9)$ \\
\hline Angina present at surgery, $\%$ & $175(71.7)$ \\
\hline \multicolumn{2}{|l|}{ NYHA FCCHF, $\%$} \\
\hline I & $58(23.8)$ \\
\hline II & $85(34.8)$ \\
\hline III & $62(25.4)$ \\
\hline IV & $39(16.0)$ \\
\hline \multicolumn{2}{|l|}{ Cine and hemodynamic data } \\
\hline Uniarterial, \% & $32(13.1)$ \\
\hline Biarterial, \% & $121(49.6)$ \\
\hline Triarterial, \% & $91(37.3)$ \\
\hline LVEF, \% & $29 \pm 4(9-35)$ \\
\hline SBP, mm Hg & $128 \pm 21(91-163)$ \\
\hline DBP, mm Hg & $77 \pm 11(65-102)$ \\
\hline PAsP, mm Hg & $57 \pm 20(24-83)$ \\
\hline PAdP, mm Hg & $29 \pm 21(13-47)$ \\
\hline LVEDP, mm Hg & $32 \pm 7(11-44)$ \\
\hline
\end{tabular}

Values represent means \pm SD unless stated otherwise. MI indicates myocardial infarction; LBBB, left bundle branch block; NYHA FCCHF, New York Heart Association Functional classification for cardiac heart failure; LVEF, left ventricular ejection fraction; $\mathrm{SBP}$, systolic blood pressure; $\mathrm{DBP}<$ diastolic blood pressure; PasP, pulmonary artery systolic pressure; PadP; pulmonary artery diastolic pressure; and LVEDP, left ventricular end-diastolic pressure

Table 2 - Surgical treatment

\begin{tabular}{lc}
\hline All grafts & 736 \\
Left internal thoracic artery & 189 \\
Right internal thoracic artery & 81 \\
Radial artery & 83 \\
Safena vein & 83 \\
Grafts/ patient & 3.01 \\
Mitral valve replacement, \% & $30(12.3)$ \\
Mitral valve repair, \% & $11(4.5)$ \\
\hline
\end{tabular}

Table 3 - Morbidity according to preoperative LVEF

\begin{tabular}{lcccc}
\hline & $<15 \%$ & $16-25 \%$ & $26-35 \%$ & $p$ value* \\
\hline n of patients & 31 & 140 & 73 & \\
ICU length-of-stay, days & $12 \pm 3$ & $7 \pm 5$ & $4 \pm 4$ & $£ 0.001$ \\
Hospital length-of-stay, days & $29 \pm 5$ & $18 \pm 5$ & $16 \pm 3$ & $£ 0.001$ \\
Dob and/or nor use, \% & $31(100)$ & $14(10)$ & $22(30.1)$ & $£ 0.001$ \\
ARF, \% & $15(48.4)$ & $13(9.3)$ & $8(11)$ & $£ 0.001$ \\
Infection, \% & $14(45.1)$ & $10(7.1)$ & $5(6.8)$ & $£ 0.001$ \\
IABP use, \% & $25(80.6)$ & $60(42.8)$ & $8(11)$ & $£ 0.001$ \\
\hline
\end{tabular}

Values represent means \pm SD unless stated otherwise. Dob indicates dobutamine; nor, norepinephrine; ARF, acute renal failure; IABP, intra-aortic balloon pump. * For means, $p$ value calculated by ANOVA oneway test; for proportions, Chi-square test. Post-hoc analysis among 3 intervals: for means, $p<0.05$; for proportions, $p<0.001$.

$p<0.001$ (fig. 2). Gated LVEF at exercise/ rest increased markedly after surgery: from $27 \pm 8 \% / 23 \pm 7 \%$ to $37 \pm 5 \% /$ $31 \pm 6 \%, p<0.001$ (figure 2). Class I and II of NYHA FCCHF was present in $30,2 \%$ and $41,6 \%$ of patients, and Class III and IV in $21,2 \%$ and $7,0 \%$, respectively.

\section{DISCUSSION}

During the last two decades, important advances on the management of patients with severe compromise of left ventricular function have remarkably altered the scenario of grafting as the use of IABP before operation improving survival and reducing hospital stay. ${ }^{6,20,21}$ Additionally, advances on myocardial preservation and resuscitation techniques, on surgical procedure by means of shorter cross clamp and cardiopulmonary bypass times, associated with the improvement on intensive postoperative care also collaborated significantly to that changes. Because of all that progress, perioperative mortality rates of $10 \%$ to $37 \%{ }^{10,11}$ was converted to the $2.5 \%$ to $8 \%$ reported on recent studies. ${ }^{5,18,19,22-28}$ In spite of the severe compromise of left ventricular function of our patients (mean LVEF of $29 \%$, ranging from $9 \%$ to $35 \%$ ), we show in-hospital mortality lower than $4 \%$ and a 4 -year survival close to $90 \%$, in agreement with the current literature. About $49 \%$ and $59 \%$ of our patients had, respectively, prior percutaneous transluminal coronary angioplasty and myocardial infarction. These data show us one more time the high rate of morbidity in patients included in this study.

In association to such development, careful examination of preoperative clinical and functional parameters also contributes significantly to determine survival, serving as a useful and valuable guide on patient selection for surgery. We observed that some preoperative variables expressively affected outcome. Multivariate analysis showed positive 

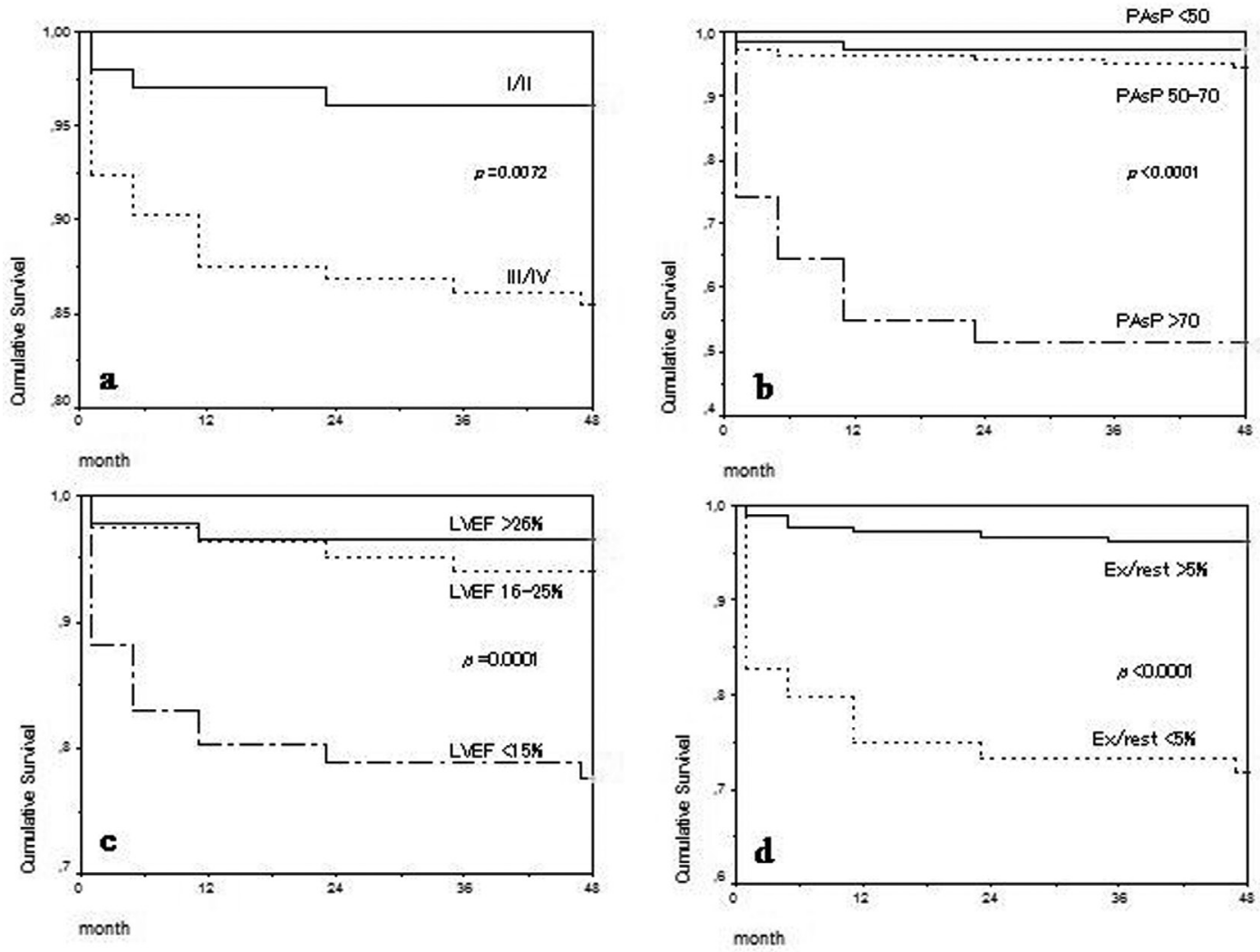

Figure 1 - Kaplan-Meier cumulative survival curves adjusted for: (a) NYHA FCCHF; (b) PasP (mmHg); (c) LVEF; (d) GATED LVEF exercice/rest

correlation between favorable short and long-term outcome and preoperative NYHA FCCHF class I/II, PAsP $<50 \mathrm{~mm}$ $\mathrm{Hg}$, gated LVEF exercise/ rest ratio $>5 \%$ and LVEF $>16 \%$. Kaplan-Meier curves demonstrate a significant difference in survival when adjusted for each of these variables. Of note, this difference became apparent since the in-hospital period and sustained statistically significant during the 4 years of follow-up (figure 1). On the contrary, when considering the more severely ill patients, in-hospital mortality was as high as $13 \%$ for patients with LVEF <15\%, $25 \%$ for PAsP $>70 \mathrm{mmHg}$, and $10 \%$ for NYHA FCCHF IV patients. Concerning clinical parameters, a report of Trachiotis and colleagues $^{16}$ identified older age, female sex, diabetes, and severity of angina class, hypertension, and NYHA FCCHF as predictive of poor survival. Isbir and associates ${ }^{17}$ observed a higher mortality for patients with elevated PAP and right ventricular failure, and Milano et $\mathrm{al}^{29}$ noted depressed cardiac index and elevated LVEDP as important predictors of mortality. Kay and coworkers ${ }^{30}$ showed that the probabilities of postoperative complications are $63 \%$ and $87 \%$ greater for patients with LVEF between $30 \%$ and $39 \%$ and LVEF $<30 \%$, respectively, compared with patients with LVEF $>40 \%$. We observed significant higher rates of length of hospitalization, infection, acute renal failure, and IABP and vasoactive drugs use for patients with $\mathrm{LVEF}<25 \%$. Taken together, these results raise two provocative issues: if there is a limit for $\mathrm{CABG}$ indication and if does exist a situation where it offers no overall benefit over medical therapy. However, they also demonstrate that preoperative clinical, hemodynamic, functional and angiographic parameters are valuable predictors of short- and long-term outcome and capable of interfering with the decision-making process. For the present, it seems reasonable to assess carefully preoperative factors in selection of candidates for surgical treatment, besides different studies have showed that in selected patients with the worst surgical therapy prognosis, medical therapy does not modify the prognosis too.,10-12,14

Another interesting issue refers to the hypothesis of recruitment of the viable muscle (hibernating myocardium), interpreted as the ability to completely revascularize ischemic myocardium. We suppose it is an even more important factor in predicting outcome than the preoperative parameters themselves. Another studies revealed better outcomes for patients who have received a higher number of grafts. $1,3,5,9-14,16,17$

Several studies demonstrate functional improvement after revascularization, either in NYHA or by means of echocardiography results. ${ }^{10,20,31}$ Salati and colleagues ${ }^{32}$ observed a small but significant global myocardial amelioration, with a $25 \%$ rise in LVEF, especially for those 

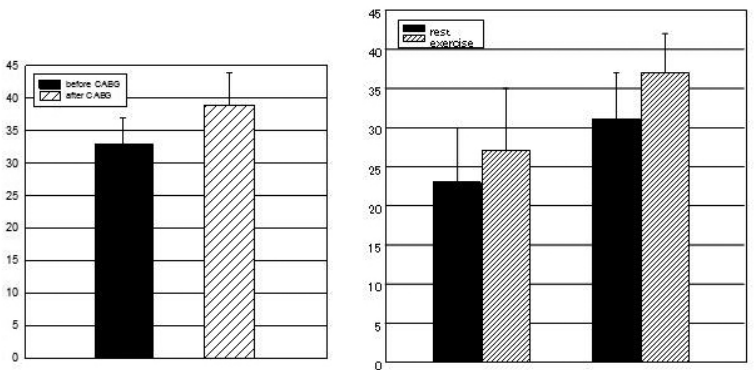

Figure 2 - Evaluation of myocardial function before and after CABG. (a) echocardiography; (b) GATED at rest/exercise

who underwent complete revascularization and showed a symmetric contraction pattern. We evaluated function through bidimensional echocardiography and, for the first time, gated scintigraphy parameters. We found a mild (12\%) but significant rise in function on echocardiography (figure 2a). Gated LVEF at exercise/ rest increased markedly (27\%/ $26 \%$, respectively) after surgery (figure $2 b$ ), which strongly corroborates the feasibility of revascularization.

Our study has limitations because of its retrospective and uncontrolled profile, yet it produces important findings.

\section{CONCLUSIONS}

Our results suggest that in selected patients with severe ischemic left ventricular dysfunction and predominance of tissue viability, CABG may be capable of implement preoperative clinical/ functional parameters in predicting outcome as left ventricular ejection fraction and gated left ventricular ejection fraction at exercise/ rest.

\section{REFERENCES}

1. Milano CA, White WD, Smith LR, Jones RH, Lowe JE, Smith PK, et al. Coronary artery bypass grafting in severe left ventricular dysfunction: excellent survival with improved ejection fraction and functional state. $\mathrm{J}$ Am Coll Cardiol. 1993;22:1411-7.

2. Christakis GT, Ivanov J, Weisel RD, Birnbaum PL, David TE, Salerno TA. Changing patterns of coronary bypass surgery. Circulation. 1989;80:I15161.

3. Shapira I, Isakov A, Yakirevich V, Topilsky M. Long term results of coronary artery bypass surgery in patients with severely depressed left ventricular dysfunction. Chest. 1995;108:1546-50.

4. Hausmann H, Ennker J, Topp H, Schüler S, Schiessler A, Hempel B, et al. Coronary artery bypass grafting and heart transplantation in end-stage coronary artery disease: a comparison o hemodynamic improvement and ventricular function. J Card Surg. 1994;9:77-84.

5. Akowuah E, Theodore S, Tatoulis J. Impact of multiple grafts to each myocardial territory on long-term survival. J Thorac Cardiovasc Surg. 2009;138:513.

6. Dietl CA, Berkheimer MD, Woods EL, Gilbert CL, Pharr WF, Benoit CH. Efficacy and cost-effectiveness os preoperative IABP in patients with ejection fraction of 0.25 or less. Ann Thorac Surg. 1996;62:401-9.

7. Onorati F, Santarpino G, Rubino A, Cristodoro L, Scalas C, Renzulli A. Intraoperative bypass graft flow in intra-aortic balloon pump-supported patients: differences in arterial and venous sequential conduits. J Thorac Cardiovasc Surg. 2009; 138:54-61.

8. Madershahian N, Liakopoulos OJ, Wippermann J, Salehi-Gilani S, Wittwer $\mathrm{T}$, Choi $\mathrm{YH}$, et al. The impact of intraaortic balloon counterpulsation on bypass graft flow in patients with peripheral ECMO. J Card Surg. 2009;24:265-8.

9. Raja SG, Siddiqui H, Ilsley CD, Amrani M. In-hospital outcomes of offpump multivessel total arterial and conventional coronary artery bypass grafting: single surgeon, single center experience. Ann Thorac Surg. 2009 ;88:47-52.

10. Alderman EL, Fisher LD, Litwin P, Kaiser GC, Myers WO, Maynard C, et al. Results of coronary artery surgery in patients with poor ventricular function (CASS). Circulation 1983;68:785-95.
11. Zubiate P, Kay JH, Mendez AM. Myocardial revascularization for patient with drastic impairment of function of the left ventricle. J Thorac Cardiovasc Surg. 1977; 73:84-6.

12. Elefteriades JA, Kron IL. CABG in advanced left ventricular dysfunction. Cardiol Clin. 1995;13:35-42.

13. Jones EL, Craver JM, Kaplan JA, King SB 3rd, Douglas JS, Morgan EA, et al. Criteria for operability and reduction of surgical mortality in patients with severe left ventricular ischemia and dysfunction. Ann Thorac Surg. 1978;25:413-24.

14. Kaul TK, Agnihotri AK, Fields BL, Riggins LS, Wyatt DA, Jones CR. Coronary artery bypass grafting in patients with an ejection fraction of twenty percent or less. J Thorac Cardiovasc Surg. 1996;111:1001-12.

15. Mickleborough LL, Maruyama H, Takagi Y, Mohamed S, Sun Z, Ebisuzaki L. Results of revascularization in patients with severe left ventricular dysfunction. Circulation. 1995;92 (suppl 2):73-9.

16. Trachiotis GD, Weintraub WS, Johnston TS, Jones EL, Guyton RA, Craver JM. Coronary artery bypass grafting in patients with advanced left ventricular dysfunction. Ann Thorac Surg. 1998;66:1632-9.

17. Selim Isbir C, Yildirim T, Akgun S, Civelek A, Aksoy N, Oz M, et al. Coronary artery bypass surgery in patients with severe left ventricular dysfunction. Int J Cardiol. 2003;90: 309-16.

18. Darwazah AK, Abu Sham'a RA, Hussein E, Hawari MH, Ismail H. Myocardial revascularization in patients with low ejection fraction $<$ or $=35 \%$ : effect of pump technique on early morbidity and mortality. J Card Surg. 2006;21:22-7.

19. Moore GJ, Pfister A, Trachiotis GD. Outcomes for off-pump coronary artery bypass grafting in high-risk groups: a historical perspective. Heart Surg Forum. 2005;8:E19-22.

20. Pigott JD, Kouchoukos NT, Oberman A, Cutter GR. Late results of surgical and medical therapy for patients with coronary artery disease and depressed left ventricular function. J Am Coll Cardiol. 1985;5:1036-45.

21. Gunstensen j, Goldman BS, Scully HE, Huckell VF, Adelman GA. Evolving indications for preoperative intraaortic balloon pump assistance. Ann Thorac Surg. 1976;22:535-45. 
22. Nishi H, Miyamoto S, Takanashi S, Minamimura H, Ishikawa T, Shimizu Y. Complete revascularization in patients with severe left ventricular dysfunction. Ann Thorac Cardiovasc Surg. 2003;9:111-6.

23. Korkmaz AA, Onan B, Onan S, Ozkara A, Guden M, Bakay C. Combined internal mammary artery graft in coronary bypass: 18-year follow-up. Ann Thorac Surg. 2009;87:e57-8.

24. Shimokawa T, Manabe S, Fukui T, Takanashi S. Remodeling of reconstructed left anterior descending coronary arteries with internal thoracic artery grafts. Ann Thorac Surg. 2009;88:54-7.

25. Schwann TA, Zacharias A, Riordan CJ, Durham SJ, Shah AS, Habib RH. Sequential radial artery grafts for multivessel coronary artery bypass graft surgery: 10-year survival and angiography results. Ann Thorac Surg. 2009;88:31-9.

26. Rocha-e-Silva R, S.G. Santos T, Rochite CE, Rocha-Filho JA, Mansur AP, Fabri Jr J, et al. Elective vs non-elective radial artery grafts: comparing midterm results through 64-Slice Computed Tomography. Clinics.2007;62:725-30

27. Subramanian S, Sabik JF 3rd, Houghtaling PL, Nowicki ER, Blackstone EH, Lytle BW. Decision-making for patients with patent left internal thoracic artery grafts to left anterior descending. Ann Thorac Surg. 2009;87:1392-8.
28. Bonello L, De Labriolle A, Lemesle G, Steinberg DH, Roy P, Xue Z, et al. Prognostic value of procedure-related myocardial infarction according to the universal definition of myocardial infarction in saphenous vein graft interventions. Am Heart J. 2009;157:894-8.

29. Milano CA, White WD, Smith LR, Jones RH, Lowe JE, Smith PK, et al. Coronary artery bypass in patients with severely depressed ventricular function. Ann Thorac Surg. 1993;56:487-93.

30. Kay GL, Sun G-W, Aoki A, Prejean, JR CA. Influence of ejection fraction on hospital mortality, morbidity and costs for CABG patients. Ann Thorac Surg. 1995;60:1640-51

31. Skorpil J, Brát R, Docekal B, Motyka O. Myocardial revascularisation in patients with severe left ventricular dysfunction. Early and midterm results. Biomed Pap Med Fac Univ Palacky Olomouc Czech Repub. 2004;148:55-8.

32. Salati M, Lemma M, Di Mattia DG, Danna P, Cialfi A, Salvaggio A, et al. Myocardial revascularization in patients with ischemic cardiomyopathy: functional observations. Ann Thorac Surg. 1997;64:1728-34. 